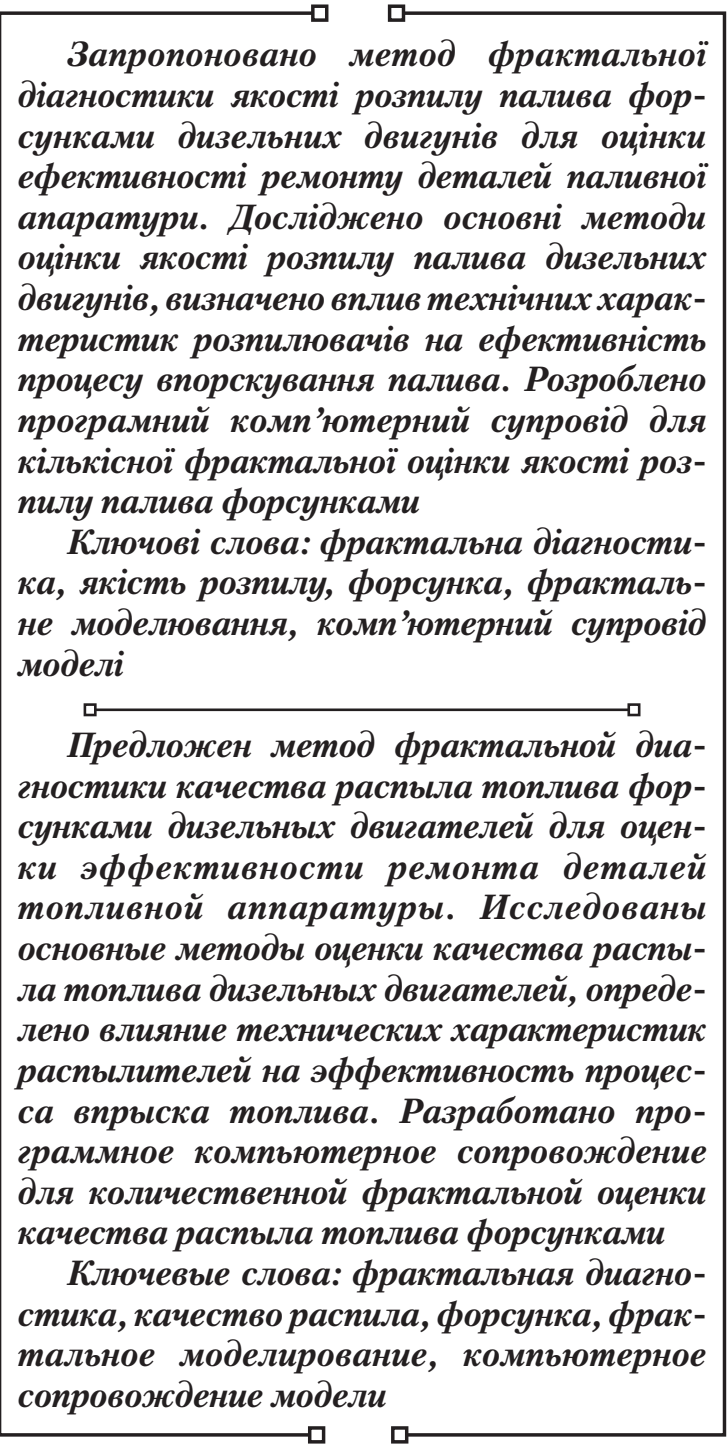

1. Introduction

Diesel engines are the primary energy sources of a large number of cars, buses, almost all tractors, combines and other equipment used in the Ukrainian economy [1]. Constant process optimization of design and production of diesel engines is achieved by improving the parameters such as engine crankshaft speed, average effective pressure and essential reduction of harmful emissions of exhaust gases [2]. Any aspects of optimizing the operation of diesel engines are directly related to the increased requirements to fuel injection equipment, which provides fuel injection pressure and, in particular, to the main injector elements - nozzles.

High mechanical, hydrodynamic and thermal loads acting in precision combinations of nozzles, insufficient lubricating properties, fuel coking, poor fuel filtration lead to a significant reduction in operational parameters and life of injector nozzles. The short life of injector nozzles, in comparison with the life of other injector elements, requires research and works to ensure the appropriate effective life. Therefore, information about defects in injector nozzles and their impact on engine performance is a starting point when solving the problem of increasing the injector nozzle life, and is an urgent problem.
UDC 629.05

DOI: $10.15587 / 1729-4061.2017 .116104$

\section{FRACTAL DIAGNOSTICS OF THE DEGREE OF FUEL ATOMIZATION BY DIESEL ENGINE INJECTORS}

\author{
S. Pustiulha \\ Doctor of Technical Sciences, Professor* \\ E-mail:mbf.dec@gmail.com \\ V. Samostian \\ PhD, Associate Professor* \\ E-mail: cvmbf@ukr.net \\ N. Tols t u sh ko \\ $\mathrm{PhD}$, Assistant \\ Department of engineering** \\ E-mail: nataleksa1978@gmail.com \\ S. Korobka \\ $\mathrm{PhD}$, Senior Lecturer*** \\ E-mail: korobkasv@ukr.net \\ M. B a b y c h \\ $\mathrm{PhD} * * *$ \\ E-mail: m.babych@ukr.net \\ *Department of engineering and computer graphics** \\ ** Lutsk National Technical University \\ Lvivska str., 75, Lutsk, Ukraine, 43018 \\ ***Department of Energy \\ Lviv National Agrarian University \\ Volodymyra Velykoho str., 1, Dubliany, Ukraine, 80381
}

2. Literature review and problem statement

There are many devices for prompt diagnostics of diesel fuel injection equipment [3-5]. The key diagnosed parameters of injector nozzles that can be monitored on these devices and test benches are:

- the degree of fuel atomization - characterized by a particle diameter, fuel spray distribution;

- leak tightness of nozzles and injectors - the ability of adjacent surfaces of parts to resist fuel leakage between them;

- leak tightness of shutter cones of injector nozzles - the ability of cones to keep fuel from leaking between contact surfaces at a given pressure drop;

- starting fuel injection pressure - fuel pressure in the channel at the injector inlet at the time of nozzle needle opening;

- nozzle needle lift - needle movement from the closed position to the fully opened position;

- injector capacity - the value characterizing the injector hydraulic resistance to fuel passage.

It should be noted that the analysis of one of the key diagnostics parameters, namely the degree of fuel atomization by injectors, is currently carried out either using too complicated and expensive methods, or at a basic, visual level at all 
(Fig. 1). A literature review has not revealed works on the development of mechanisms for quantifying the quality of the fuel spray in case of repair when the injector is located on a test bench, and not in the engine.

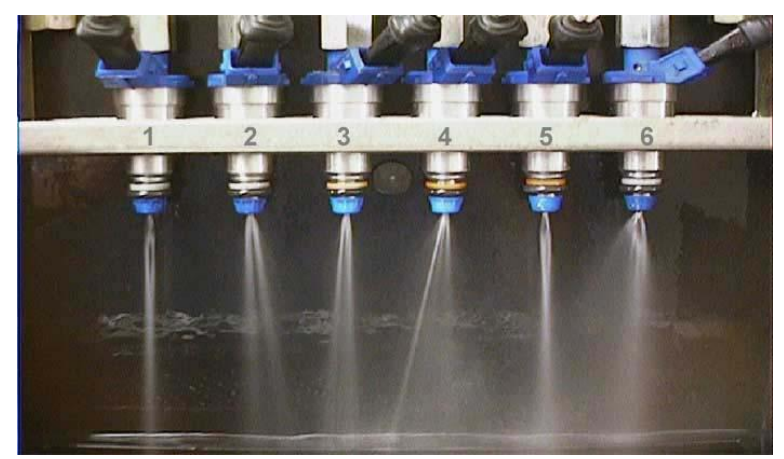

Fig. 1. Visual assessment of the degree of fuel atomization by injectors

However, it is known that for some physical processes of mixture formation, even the parameters such as the area or the volume of interaction between the elements are not decisive, since they tell nothing about spatial particle distribution. The volume and the area may be the same for both the steam and the puddle of a certain mixture.

On the other hand, fuel traces on paper during injection resemble a stochastic fractal, which a priori has fractal dimension. When studying a number of fractal values of the fuel spray or mixture spots obtained from the injection by nozzles of different designs, it is possible to instantly and quantitatively estimate the degree of fuel atomization by injectors. Thus, insufficiency and even lack of studies on the connection of fractal modeling methods with optimization of diagnostics of fuel injection equipment of diesel engines determine the relevance of this research.

Energy efficiency, environmental friendliness, power and other engine characteristics depend on the degree of fuel atomization. The degree of fuel atomization by diesel injectors is determined by droplet fineness, dispersion uniformity, and also uniformity of fuel droplet distribution in the jet volume.

The above characteristics are required, but they depend on a number of input characteristics. First of all, these include fuel injection pressure, fuel viscosity index, nozzle hole diameter, nozzle body flow channel geometry. In practice, the degree of fuel atomization by diesel injectors can be analyzed based on the results of studying the fuel jet structure, as well as on measurements of the nozzle body flow channel geometry, since the geometry has the greatest effect.

Existing computational and experimental methods for the fuel jet structure diagnostics can be divided into two groups: direct and indirect [6,7].

The first group, that is, direct methods, includes:

- high-speed microfilming (photomicrography). In microfilming, photographing of a jet is carried out with a high-speed camera, followed by frame-by-frame analysis of changes in one jet in time and space;

- stroboscopy. In stroboscopy, synchronization of a stroboscope with the beginning of fuel leakage is carried out to record changes in a set of jets at a certain time point;

- taking droplet prints on a contact surface. The method of taking droplet prints on the perceiving surface has a drawback - fuel droplets are deformed due to the mechanical influence of the surface, which distorts measurements;
- the method based on solidification of atomized liquid droplets in a refrigerant gas medium. This method also has a drawback - it involves atomization not of fuel, but an easily solidifying liquid, such as liquid paraffin. This also distorts a jet atomization picture in real conditions.

The second group includes the methods based on the use of different patterns depending on the droplet size distribution function: photometry, holographic method, optical methods (diffraction).

Optical methods are the most effective. They use the effects of a disperse flow on light radiation, since in this case there is no any mechanical influence on the atomization process under study. One of the most common optical methods for determining the jet particle size distribution function is small-angle scattering (SAS) [8]. It is based on measuring the function of scattering of a plane light wave at small angles after passage through a medium containing disperse particles.

For investigations of the fuel jet structure, a so-called laser knife is used, which provides longitudinal (Fig. 2,a) and cross (Fig. 2, $b$ ) jet sections. The advantage of this method is the absence of influence on the physical processes that occur in a fuel jet.

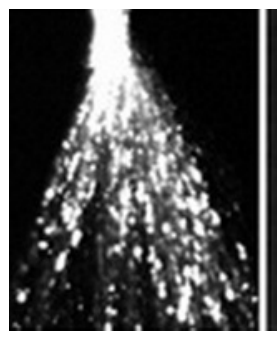

a

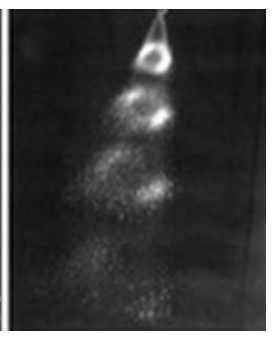

$b$
Fig. 2. Examples of visualization of the fuel jet section: $a$ - longitudinal section; $b$ - cross section

On the other hand, since the end of the last century, the subject of the practical use of fractal structures for the analysis of various complex processes has confidently occupied one of the leading positions. Moreover, different structures are considered, ranging from traditional (geometric) up to those that have become popular rather recently (geophysical, economic, medical, physical, thermodynamic).

In [9], the effectiveness of leakage in radial permeability and relative permeability for spherical leakage in porous media has been studied using the theory and the method of fractal action for porous media. In [10], a mercury intrusion test for pyrosimetry has been conducted, a comprehensive examination of fractality in a cement particle, which could be a pore mass fractal, pore surface fractal, or solid fractal has been carried out. In [11], various fractal/multifractal models based on scale characteristics of geochemical data for quantification of the spatial distribution of geochemical data have been proposed.

The Higuchi fractal dimension is a very good, fast and universal method for modeling the evolution of trends in the national economy concentration. In [12], the fractal dimension has given information on more or less chaotic distribution in space according to the number of companies, profit, number of employees, and turnover.

Fractal structures and fractal dimension were used in medicine [13], where fractal models of normal contact stiffness between two spheroidal joint surfaces were studied, 
taking into account the coefficient of friction. Numerical results show that the relationship between normal contact stiffness and normal load is a direct or inverse relation, determined by the magnitude of fractal dimension. In [14], the method of oriented analysis, combining an anisotropic fractional model of Brownian motion with effective fractal dimension estimation, called anisotropic piecewise Whittle estimator (ap-WhE), has been proposed for better characterization of trabecular changes in bone radiographs.

The fractal theory is of equal importance in such fields of science as physics and thermodynamics. In particular, the model of fractal continuum considering the topological, metric and dynamic properties of a deformed physical fractal medium has been proposed in [15]. In [16], the Newtonian grid has been replaced with a fractal grid and the effect of damage has been considered, which resulted in a new constitutive model in terms of fractal time derivative to describe the entire area of granite creep.

The works on thermodynamics deal with fractal models for effective thermal conductivity of the porous medium [17] and airgel with silica, taking into account the heat transfer channel sinuosity and the secondary particle microstructure [18].

However, no works on the interrelationship between the fractal dimension of point geometric structures and the degree of fuel atomization by injectors on different contact surfaces have been found.

\section{The aim and objectives of the study}

The research was aimed at elaborating a method of fractal diagnostics of the degree of fuel atomization by diesel engine injectors and developing an algorithm for computer implementation of the proposed approaches. This will allow a prompt and thorough fractal diagnostics of injectors to assess the degree of fuel atomization.

To achieve this aim, the following objectives were accomplished:

- to analyze the known methods of fractal modeling of objects with fractal dimension in order to use their components for the development of algorithms for fractal diagnostics of fuel atomization spots;

- to develop a method and an algorithm for quantitative fractal diagnostics of the efficiency of diesel engine injector nozzles;

- to carry out computer implementation of algorithms for estimating the fractal dimension of spots of fuel atomized by injectors.

\section{Materials and methods of research on \\ fractal diagnostics of the degree of fuel atomization by diesel engine injectors}

\footnotetext{
4. 1. Method of determining the fractal dimension of spots of fuel atomized by injectors

As a rule, fractal structures are generated by complex systems, the description of which in the form of differential equations or discrete mappings is challenging. However, it is well established that such geometric objects are usually fractals [19]. This means that, despite the extreme irregularity, their behavior remains unchanged on all scales, up to the minimum [20].
}

The main characteristic of such self-similar structures is known to be the dimension $D$, introduced by Hausdorff for compact sets in an arbitrary metric space. If an approximation of the graphs of fractal objects is considered as complexes consisting of simple two-dimensional figures (e.g., cells) with a geometric index $\delta$, then, as follows from the Hausdorff definition, the dimension $D$ is determined from the power law:

$$
N(\delta) \sim(1 / \delta)^{D} \text { with } \delta \rightarrow 0,
$$

where $N(\delta)$ is the number of cells in the complex with a scale $\delta$.

However, in the practical attempt to find $D$ directly from the formula (1), there is a serious problem. It is due to the fact that, on the one hand, real point sets always have the minimum scale of the structure $\delta_{0}$, and on the other hand, for all known approximations, asymptotic approximation (1) is usually very slow.

In [21], an approach where such a sequence of cell approximations for fractal point sets occurs automatically has been proposed. The idea is to introduce a new concept: the fractality index $\mu$ and the minimum cover dimension $D_{\mu}$. It is shown that the use of the index $\mu$ allows revealing a power law for these discrete sets, which is fulfilled with incredible accuracy. When comparing the index $\mu$ with other fractal indicators, it turns out that reliable determination of this index with an acceptable accuracy requires two orders of magnitude less data than, for example, determination of the Hurst index $H$.

If both parts of (1) are multiplied by $\delta^{2}$, the definition of dimension can be rewritten in the form of a power law for the approximation area $S(\delta)$ :

$$
S(\delta) \sim \delta^{2-D} \text { with } \delta \rightarrow 0 .
$$

Note that this form, in contrast to (1), does not require that the simplexes of approximation are the same. It is enough that they have the same geometric factor $\delta$. This will allow using the approximations, which, at a given $\delta$, in a sense, best approximate the initial function. However, the mathematical description of discrete fractal sets and calculation of the areas by the proposed simplexes are ineffective.

At the same time, such fractal structures can be described rather easily by the method of discrete vector modeling of geometric images proposed in $[22,23]$. In this case, it is proposed to determine local geometric parameters of fractals by characteristics of forming forces [24] of the static-geometric method, and determine the fractal dimension of either given or modeled fractal sets through the values of forces in the nodes.

Suppose the method [24] models a section of the boundary of a fractal point set that characterizes the degree of atomization by diesel engine injectors. By analyzing the boundary of the set (Fig. 3, a), we allocate the section with an affinity-like structure for the entire boundary series (Fig. 3, b), that is, a certain interval $A-t_{i-1} \ldots . . . t_{m}$ (Fig. 3, $c$ ).

Then the geometric characteristics of the cell's scale will be determined by $t_{i}-t_{i-1}=g=\left(t_{i}-t_{0}\right) / n(i=1,2, \ldots, n)$ (Fig. 4). For a set of allocated points of a discrete series, we construct a system of finite-difference equations of the static-geometric method:

$$
x_{i-1}-2 x_{i}+x_{i+1}+k P_{i}^{x}=0 \text {, }
$$




$$
y_{i-1}-2 y_{i}+y_{i+1}+k P_{i}^{y}=0
$$

whereby we find the values of the components of the forming forces $P_{i}^{x}, P_{i}^{y}$ in the nodes of the boundary broken fractal structure (Fig. 4).

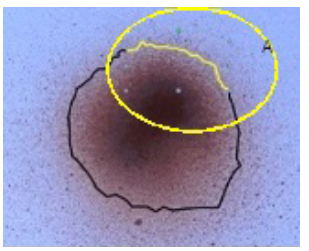

a

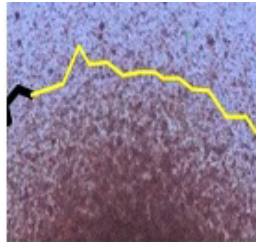

$b$

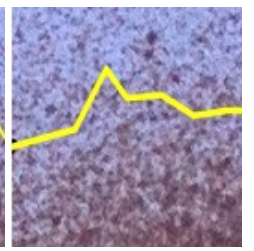

C
Fig. 3. Characteristic boundary of a point set of the atomization spot: $a$ - spot boundary; $b$ - local spot section; $c$ - certain spot interval

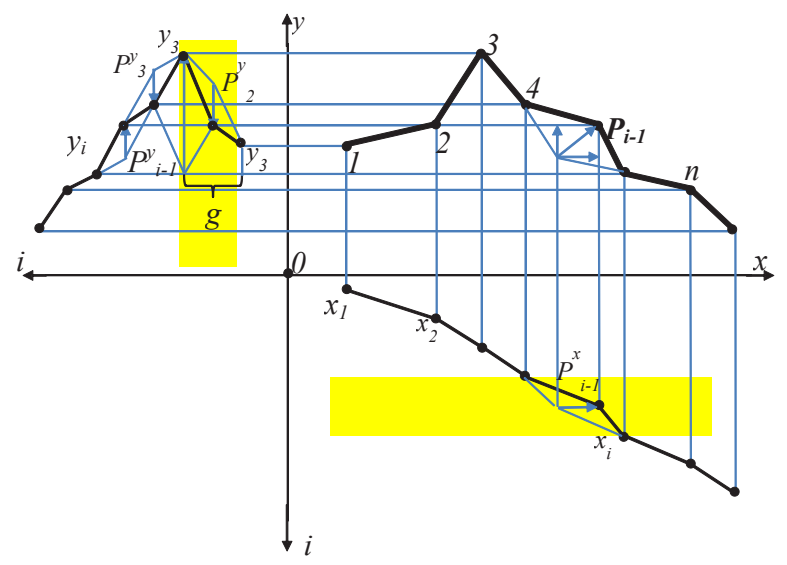

Fig. 4. Model of characteristic boundary series

The graph of these vectors indirectly characterizes the "fractality value" of the allocated fragment. The greater the oscillation of the forming load values relative to the axis, the greater the fractal dimension of the geometric object (Fig. 4), ranging from 1 to 2.

In [24], the graph of the allocated area has been covered with rectangles so that this cover had the minimum area in the class of rectangle covers with a step $\delta$. The behavior of the minimum $S(\delta)$ on the graph on the double logarithmic scale gave the effect of rapid approach to an asymptote even at high values of the step $\delta$. The areas of cover were found using the fractal object amplitude.

$$
D_{\min }=2-\frac{\ln \sum_{i=1}^{n-1} \frac{1}{4} P_{i}^{y}(\delta) \cdot \delta}{\ln \delta} .
$$

In the expression (4), we see that the minimum cover dimension is practically expressed and depends on the distribution of the external forming load $P_{i}^{y}(\delta)$ in the nodes of the fractal structure (Fig. 4).

The fractality index, which is the point boundary series identifier, is determined from the expression: $\mu=D_{\min }-1$ (Fig. 5), after which it is possible to construct the local fractal analysis of a point discrete series using the function $\mu(\mathrm{t})$.

Test cases have shown that, with different methods of calculating the fractal dimension of the same fractal object, the fastest approach to an asymptote occurs when using the proposed method.

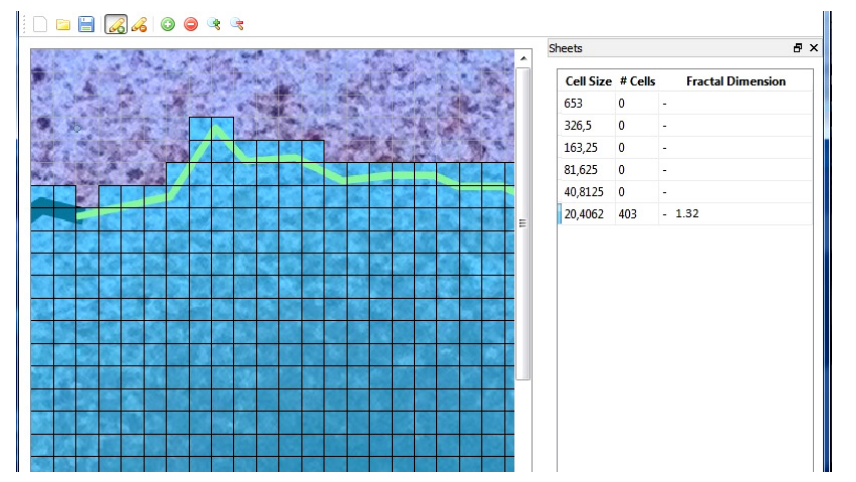

Fig. 5. Determination of the fractal dimension index

4. 2. Experimental research on the degree of fuel atomization by injectors using the developed method

According to the proposed method of fractal diagnostics, we conduct the experimental research of the degree of fuel atomization by diesel engine injectors. To do this, we diagnose different types of diesel injector nozzles on the KI-562D device (Fig. 6).

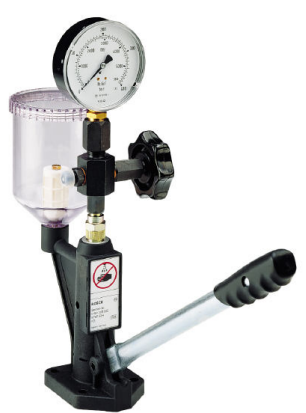

Fig. 6. General view of the KI-562D device

Using this device for injector testing, it is possible to adjust the pressure of opening of the injectors examined, and also to check leakage, atomization and noise.

The device was fitted with a reference injector. The required injection pressure was generated and a number of spots of diesel fuel atomized by reference injector nozzles were obtained on paper. All basic geometric parameters such as the angles of inclination of the test sample to the spot application surface and the distance from the injector nozzle to this surface were measured.

Further, with fixed geometric parameters of all distances and angles, images of reference spots were obtained using a camera, the examples of which are shown in Fig. $7 a, b$.

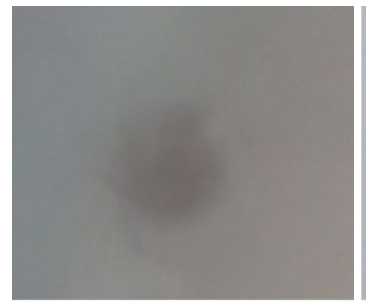

$a$

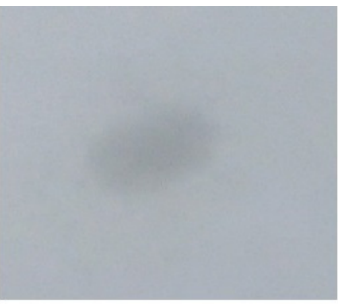

$b$
Fig. 7. Samples of spots of fuel atomized by reference injector nozzles: $a$ - atomization spot from the first injection of the reference injector; $b$ - atomization spot from the second injection of the reference injector 
The method of comparing the atomization spots and determining the fractal dimension directly depends on identical conditions of photographing the required spots. These conditions include diesel fuel color, injector nozzle opening pressure, the distance from the injector nozzle to the paper, which shows the atomization spot, the angle between the paper and the centered injector nozzle.

In addition, the resulting images should be converted to a single format. For this, the spot images should be converted into images of the same and fixed size (1500 $\mathrm{p}$ in width). This dimension was chosen as the most effective for calculating the fractal dimension of the images.

In order that the fractal identification algorithm was more resistant to light conditions, all color images were converted into grayscale ones.

The intensity of the grayscale image pixel is calculated by the following formula:

$$
I I=0,29 R+0,58 G+0,13 B
$$

where $I I$ is the intensity of the grayscale image pixel, $R$ is the intensity of the red image channel, $G$ is the intensity of the green image channel, $B$ is the intensity of the blue image channel.

Like any other image recognition system, the system of fractal identification of spots of fuel atomized by diesel engine injectors involves several standard procedures.

The first procedure is the atomization spot image segmentation, that is, setting the limits of the intensity of droplets in the image. Allocation of a segment, which will be considered further in the analysis and determination of the fractal dimension, is related to the distance between the individual spot particles (Fig. 8). The distance should not exceed 3p.

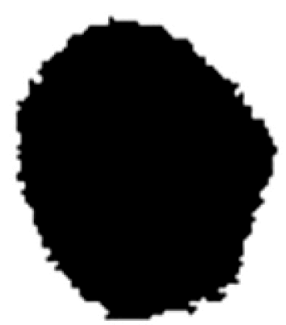

Fig. 8. Segmented and allocated skeleton of the spot of fuel atomized by an injector

To normalize the spot images for calculating the dimension, it is needed first to allocate the image, that is, to determine the boundaries. For image allocation, an image skeleton calculation procedure is performed. An example of the ready normalized atomization spot is shown in Fig. 9.

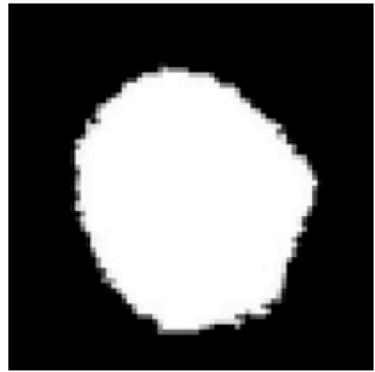

Fig. 9. Normalized atomization spot
Fig. 10, $a-d$ show a frame-by-frame calculation of the fractal dimension of the spot of fuel atomized by the reference injector.

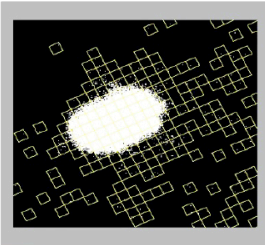

$a$

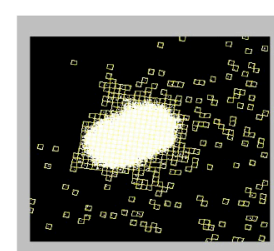

$d$

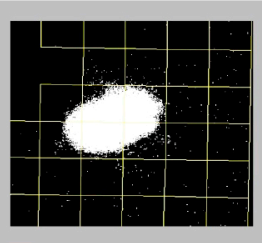

$b$

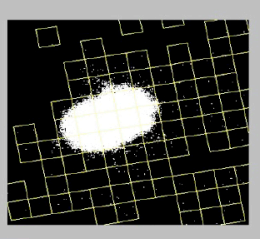

C

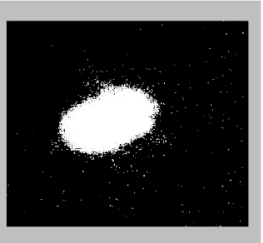

e

Fig. 10. Software algorithm for calculating the fractal dimension of the spot of fuel atomized by the reference

injector: $a$ - the first frame; $b$ - the second frame; $c$ - the third frame; $d-$ the fourth frame; $e-$ the fifth frame

Using the above method of preparing images for reading the fractal dimension indicators, we run the FrakOut program for quantitative assessment of the spot dimensions. By (4), it is easy enough to calculate the fractal dimension of the reference samples.

\section{Results of the research on quantitative fractal} characteristics of fuel atomization spots

The fractal dimension of ten samples of diesel fuel atomized by the reference injector ranged from 1.29 to 1.31 fractal units.

Then, two different repaired injectors with the same geometric parameters were examined on the same test bench. The examples of spots of fuel atomized by two different repaired injectors are shown in Fig. $11 a, b$.
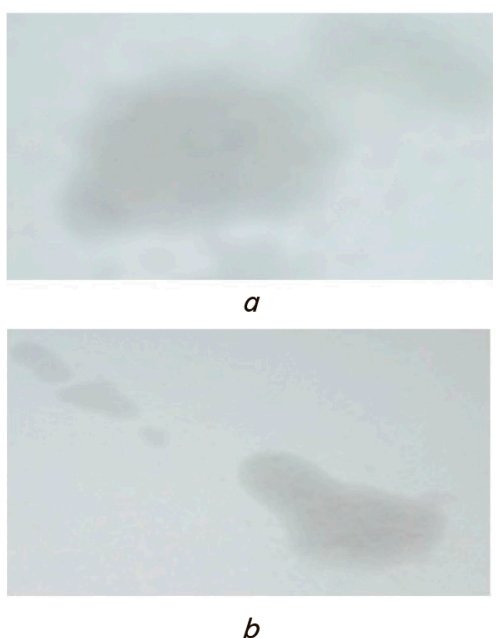

Fig. 11. Samples of spots of fuel atomized by the repaired injectors: $a-$ the first repaired injector; $b-$ the second repaired injector 
Similarly to the procedures with the spots of fuel atomized by the reference injector, studies with the spots of fuel atomized by two repaired injectors were carried out (Fig. 12, $a, b$ ).

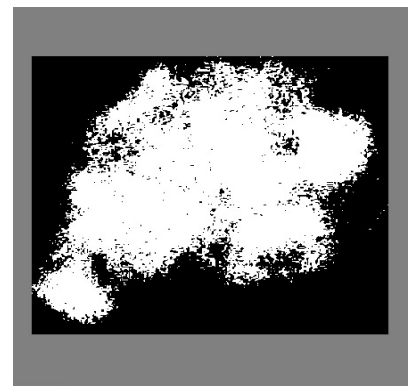

$a$

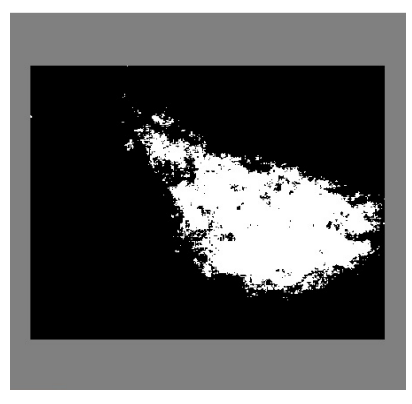

$b$

Fig. 12. Result of the program of calculating the fractal dimension of the spots of fuel atomized by the repaired injectors: $a$ - the first repaired injector; $b$ - the second repaired injector

The fractal dimension of the spots of fuel atomized by two different repaired injectors $(1.7-1.83)$ is much greater than the dimension in case of the reference injector (1.29-1.31).

\section{Discussion of the results of the research on quantitative fractal parameters of fuel atomization by injectors}

As a result of the experimental research using the proposed method of fractal diagnostics, it was found that the value of the fractal dimension of the spots of fuel atomized by the reference injector ranged from 1.29 to 1.31 fractal units. The fractal dimension of the spots of fuel atomized by the repaired injectors ranged from 1.67 to 1.85 fractal units. These results confirmed the expectations and the results of operation of nozzles on the uniform distribution of fuel droplets in the jet volume by the reference injector. So, the structure and boundaries of the spray for the reference injector in the images of the spots were regular and characterized by a low fractal dimension.

During the operation of engine nozzles, the nozzle geometry, the nozzle body flow channel, as well as the bedding degree of precision pairs, change. The structure of the spots of fuel atomized by the repaired injectors becomes irregular, and the boundaries of the spots become scattered, which affects the growth of the fractal dimension of the object under study.

In the process of experiments and using the developed method of fractal diagnostics of injectors, it was revealed that the accuracy of determining the fractal characteristics of atomization objects significantly depends on:

1. Physical characteristics of diesel fuel (color, content of impurities, additives, etc.), used on a laboratory installation for injector testing.

2. Physical and geometric parameters of the surface, on which the fuel was atomized by the injectors examined.

3. Clarity and identity of the processes of photometry and computer-aided preparation of images of the spots of fuel atomized by injectors for determining the fractal dimension parameters.

The experiment and subsequent attempts to use the repaired injectors showed that when they formed atomization spots with a dimension of up to 1.38 fractal units, the normal performance of the repaired injector is restored by washing the elements of precision pairs and cleaning the nozzles.

With the fractal dimension of the spots of fuel atomized by the repaired injector greater than 1.40 fractal units, the injector nozzle should be replaced for further operation.

Additional research is planned to be carried out in the direction of generalizing the dependencies of the fractal dimension of atomization spots on the wear rate of precision pairs in the repaired injectors with the construction of special diagnostics schedules.

\section{Conclusions}

1. The method of quantitative fractal diagnostics of diesel engine injector nozzles is proposed. It is based on the analysis of the known methods of fractal modeling of objects with fractal dimension and the correction of fractal algorithms for evaluating the fractal characteristics of point sets that can serve as a model of fuel droplets in the atomization spots of engine injectors.

2. The computer implementation of the algorithm for estimating the fractal dimension of point sets with fuzzy boundaries is proposed. Its feature is the identification of images of fuel atomization spots, based on the theory of fractal modeling and the concept of fractal dimension.

3. The experimental research of the degree of fuel atomization by the repaired injectors was carried out, which confirmed the hypothesis of a direct dependence of the fractal dimension of spots on the wear rate of precision pairs used in fuel injection equipment. The experimental research showed that the fractal dimension of the spot of fuel atomized by the diagnosed injector allows drawing conclusions about the readiness of operation on an engine or about the need for repairing such an injector.

1. Turevskiy, I. S. Tekhnicheskoe obsluzhivanie avtomobiley. Ch. 1. Tekhnicheskoe obsluzhivanie i tekushchiy remont avtomobiley [Text] / I. S. Turevskiy. - Moscow: ID «Forum» - INFRA-M, 2011. - 432 p.

2. Krivenko, P. M. Remont i tekhnicheskoe obsluzhivanie sistemy pitaniya avtotraktornyh dvigateley [Text] / P. M. Krivenko, I. M. Fedosov. - Moscow: Kolos, 2006. - 288 p.

3. Zaharov, Yu. A. Analiz oborudovaniya, primenyaemogo dlya diagnostiki, ispytaniya i proverki forsunok dizel'nyh DVS avtomobiley [Text] / Yu. A. Zaharov, E. A. Kul'kov // Molodoy ucheniy. - 2015. - Issue 2. - P. 154-157. 
4. Maetskiy, A. V. Obzor priborov i metodov issledovaniya kachestva raspylivaniya topliva dizel'noy forsunkoyu [Text] / A. V. Maetskiy, A. A. Greben'kov // Molodoy ucheniy. - 2011. - Issue 10. - P. 48-54.

5. Novichkov, A. V. Issledovanie iznashivaniya pretsizionnyh detaley dizel'noy toplivnoy apparatury [Text] / A. V. Novichkov, E. V. Novikov, E. G. Rylyakin, A. V. Lahno, P. I. Anoshkin // Mezhdunarodniy nauchniy zhurnal. - 2014. - Issue 3. - P. $108-111$.

6. Zaharov, Yu. A. Proverka, diagnostika i ispytanie forsunok dizeley [Text] / Yu. A. Zaharov, E. G. Rylyakin // Transport. Ekonomika. Sotsial'naya sfera. Aktual'nye problemy i ih resheniya: sbornik statey Mezhdunarodnoy nauchno-prakticheskoy konferentsiy MNITS PGSKHA. - Penza: RIO PGSKHA, 2014. - P. 43-47.

7. Filin, I. N. Ustroystvo dlya proverki forsunok dizeley [Text] / I. N. Filin //Vklad molodyh uchenyh v innovatsionnoe razvitie APK Rossii: sbornik materialov Vserossiyskoy nauchno-prakticheskoy konferentsii. - Penza: RIO PGSKHA, 2013. - P. $204-206$.

8. Trelin, A. A. Osnovnye pokazateli tekhnicheskogo sostoyaniya forsunok - davlenie nachala vpryska, kachestvo raspylivaniya topliva, germetichnost' i propusknaya sposobnost' [Text] / A. A. Trelin, K. V. Trelina // Trudy GOSNITI. - 2007. - Vol. 99. - P. 61-63.

9. Miao, T. A fractal model for spherical seepage in porous media [Text] / T. Miao, B. Yu, Y. Duan, Q. Fang // International Communications in Heat and Mass Transfer. - 2014. - Vol. 58. - P. 71-78. doi: 10.1016/j.icheatmasstransfer.2014.08.023

10. Gao, Y. Examination and modeling of fractality for pore-solid structure in cement paste: Starting from the mercury intrusion porosimetry test [Text] / Y. Gao, K. Wu, J. Jiang // Construction and Building Materials. - 2016. - Vol. 124. - P. $237-243$. doi: 10.1016/j.conbuildmat.2016.07.107

11. Zuo, R. Fractal/multifractal modeling of geochemical data: A review [Text] / R. Zuo, J. Wang // Journal of Geochemical Exploration. - 2016. - Vol. 164. - P. 33-41. doi: 10.1016/j.gexplo.2015.04.010

12. Andronache, I. C. Using Fractal Analysis in Modeling Trends in the National Economy [Text] / I. C. Andronache, D. Peptenatu A.-M. Ciobotaru, A. K. Gruia, N. M. Gropo il // Procedia Environmental Sciences. - 2016. - Vol. 32. - P. 344-351. doi: 10.1016/ j.proenv.2016.03.040

13. Chen, Q. Research on fractal model of normal contact stiffness between two spheroidal joint surfaces considering friction factor [Text] / Q. Chen, F. Xu, P. Liu, H. Fan / Tribology International. - 2016. - Vol. 97. - P. 253-264. doi: 10.1016/j.triboint.2016.01.023

14. Harrar, K. Oriented fractal analysis for improved bone microarchitecture characterization [Text] / K. Harrar, R. Jennane, K. Zaouchi, T. Janvier, H. Toumi, E. Lespessailles // Biomedical Signal Processing and Control. - 2018. - Vol. 39. - P. 474-485. doi: 10.1016/j.bspc.2017.08.020

15. Balankin, A. S. Stresses and strains in a deformable fractal medium and in its fractal continuum model [Text] / A. S. Balankin // Physics Letters A. - 2013. - Vol. 377, Issue 38. - P. 2535-2541. doi: 10.1016/j.physleta.2013.07.029

16. Wang, R. A fractal derivative constitutive model for three stages in granite creep [Text] / R. Wang, Z. Zhuo, H. W. Zhou, J. F. Liu // Results in Physics. - 2017. - Vol. 7. - P. 2632-2638. doi: 10.1016/j.rinp.2017.07.051

17. Shen, H. Anisotropic fractal model for the effective thermal conductivity of random metal fiber porous media with high porosity [Text] / H. Shen, Q. Ye, G. Meng // Physics Letters A. - 2017. - Vol. 37. - P. 3193-3196. doi: 10.1016/j.physleta.2017.08.003

18. Li, Z.-Y. A multi-level fractal model for the effective thermal conductivity of silica aerogel [Text] / Z.-Y. Li, H. Liu, X.-P. Zhao, W.-Q. Tao // Journal of Non-Crystalline Solids. - 2015. - Vol. 430. - P. 43-51. doi: 10.1016/j.jnoncrysol.2015.09.023

19. Falconer, K. Fractal Geometry: Mathematical Foundations and Applications [Text] / K. Falconer. - Wiley, 2003. doi: 10.1002/0470013850

20. Mandel'brot, B. Fraktal'naya geometriya prirody [Text] / B. Mandel'brot. - Moscow: In-t komp'yuternyh issled., 2002. - 656 p.

21. Feder, E. Fraktaly [Text] / E. Feder. - Moscow: Mir, 1991. - 254 p.

22. Pustiulha, C. I. Dyskretne vektorne formuvannia heometrychnykh obiektiv [Text] / C. I. Pustiulha // Prykladna heometriya ta inzhenerna hrafika. - 2011. - Issue 88. - P. 271-278.

23. Pustiulha, S. I. Dyskretne vyznachennia heometrychnykh obiektiv chyslovymy poslidovnostiamy [Text]: dys. ... d-ra tekhn. nauk / S. I. Pustiulha. - Kyiv, 2006. -320 p.

24. Pustiulha, C. I. Dyskretne vektorne formuvannia fraktalnykh struktur [Text] / C. I. Pustiulha, V. M. Prydiuk, I. V. Prushko // Naukovi notatky. - 2012. - Issue 37. - P. 275-279. 